\title{
Article
}

\section{Sugary Liquids in the Baby Bottle: Risk for Child Undernutrition and Severe Tooth Decay in Rural El Salvador}

\author{
Priyanka Achalu ${ }^{1, *(1)}$, Abhishek Bhatia $\left.{ }^{2}{ }^{(}\right)$, Bathsheba Turton ${ }^{3}\left(\mathcal{B}\right.$, Lucy Luna $^{4}$ and Karen Sokal-Gutierrez ${ }^{1(\mathbb{C})}$ \\ 1 School of Public Health, University of California, Berkeley, Berkeley, CA 94720, USA; ksokalg@berkeley.edu \\ 2 FXB Center for Health and Human Rights, The Lakshmi Mittal and Family South Asia Institute, \\ Harvard University, Cambridge, MA 02138, USA; abhi@mail.harvard.edu \\ 3 Department of Dentistry, University of Puthisastra, Phnom Penh 12211, Cambodia; bethy.turton@gmail.com \\ 4 Asociación Salvadoreña Pro Salud Rural (ASAPROSAR), Santa Ana 02201, El Salvador; \\ direccionasaprosar2016@gmail.com \\ * Correspondence: pachalu@berkeley.edu; Tel.: +1-408-839-2691
}

Citation: Achalu, P.; Bhatia, A. Turton, B.; Luna, L.; Sokal-Gutierrez, K. Sugary Liquids in the Baby Bottle: Risk for Child Undernutrition and Severe Tooth Decay in Rural El Salvador. Int. J. Environ. Res. Public Health 2021, 18, 260. https://doi.org/ $10.3390 /$ ijerph18010260

Received: 18 November 2020 Accepted: 28 December 2020 Published: 31 December 2020

Publisher's Note: MDPI stays neutral with regard to jurisdictional clai$\mathrm{ms}$ in published maps and institutional affiliations.

Copyright: (C) 2020 by the authors. Licensee MDPI, Basel, Switzerland. This article is an open access article distributed under the terms and conditions of the Creative Commons Attribution (CC BY) license (https:// creativecommons.org/licenses/by/ $4.0 /)$.

\begin{abstract}
As communities worldwide shift from consuming traditional diets to more processed snacks and sugar-sweetened beverages (SSBs), increases in child obesity and tooth decay and persistence of undernutrition are particularly apparent in Latin American countries. Further evidence of shared risk factors between child undernutrition and poor oral health outcomes is needed to structure more effective health interventions for children's nutrition. This study aims to identify dietary, oral health, and sociodemographic risk factors for child undernutrition and severe early childhood caries (sECC) among a convenience sample of 797 caregiver-child pairs from rural Salvadoran communities. Caregiver interviews on child dietary and oral health practices were conducted, and their children's height, weight, and dental exam data were collected. Multivariable regression analyses were performed using RStudio (version 1.0.143). Caregiver use of SSBs in the baby bottle was identified as a common significant risk factor for child undernutrition $(p=0.011)$ and sECC $(p=0.047)$. Early childhood caries $(p=0.023)$ was also a risk factor for developing undernutrition. Future maternalchild health and nutrition programs should coordinate with oral health interventions to discourage feeding children SSBs in the baby bottle and to advocate for policies limiting SSB marketing to young children and their families.
\end{abstract}

Keywords: child undernutrition; nutrition transition; artificial feeding; dental caries; sugar-sweetened beverages; risk factors; caregivers; El Salvador

\section{Introduction}

The "nutrition transition", characterized by a global shift from traditional, whole-food diets to foods and beverages that have high sugar, fat, and salt content, has been driven by global increases in urbanization, trade liberalization, and food marketing [1]. The consequences of this transition are felt mostly in low-to-middle-income countries, and over recent decades, Latin America specifically has seen an increased consumption of fat and sugar and decreased intake of fresh fruit and vegetables [1,2]. Prior research has highlighted the link between this shift in dietary patterns and malnutrition: the deficiency, excess, or imbalance in an individual's consumption of energy and nutrients [3]. As the global nutrition landscape changes, the literature has especially noted the double burden of malnutrition, where the prevalence of obesity increases while undernutrition persists [4]. Young children who are still growing and developing are especially vulnerable to these nutrition-related diseases [4]. Children with malnutrition, which includes both overweight/obesity and undernutrition, are at higher risk for overall poorer health, development, and quality of life and for tooth decay $[4,5]$.

Tooth decay (dental caries) is the most common chronic childhood disease worldwide, affecting $60-90 \%$ of children worldwide, and studies have also demonstrated that children 
with severe dental caries are at higher risk for poor nutrition outcomes [6-8]. While many factors contribute to the progression of dental caries such as diet, oral bacteria biofilm, poor oral hygiene, and socioeconomic conditions, research has recognized dietary sugars as the main driver of this disease $[9,10]$. Research has attributed the coexistence of malnutrition and early childhood caries (ECC) - the presence of one or more decayed teeth in a child under age 6-to a shared set of risk factors including frequent consumption of processed foods and sugar-sweetened beverages, and severe caries leading to chronic dental infection, inflammation and mouth pain, and subsequent malnutrition [7,11]. However, the mechanisms by which ECC negatively impacts a child's nutrition are not fully understood [12,13].

El Salvador, like other low-to-middle-income countries, experiences the double burden of malnutrition [14,15]. While approximately 1 in 4 children living in rural El Salvador experience chronic undernutrition, obesity has become an emerging public health problem; $6 \%$ of all Salvadoran children under the age of 5 are overweight or obese, increasing to $49 \%$ by adulthood [4,16]. In El Salvador, over 50\% of young children also experience ECC [17]. Because access to dental services is limited for much of the Salvadoran population, most cavities resulting from tooth decay remain untreated, which can cause mouth pain, difficulty eating and sleeping, poor school performance, and an overall worsened quality of life $[8,18]$. While existing studies have documented the effects of the nutrition transition on children's nutrition status in broader Latin American contexts, its effects in rural El Salvador specifically remain unclear [19].

This study is an exploratory analysis aiming to identify dietary, oral health, and sociodemographic risk factors for child undernutrition and severe early childhood caries (sECC) for rural communities in El Salvador.

\section{Materials and Methods}

\subsection{Study Population}

The study population included a cross-sectional convenience sample of mothers and children in El Salvador who were beneficiaries of the local Salvadoran partner Asociación Salvadoreña Pro Salud Rural (Salvadoran Association for Rural Health, ASAPROSAR). ASAPROSAR is a not-for-profit, nongovernmental community health and development program that works with community health workers (promotoras de salud) to promote maternal and child health practices for low-income, low-literacy, and resource-poor communities in the rural Santa Ana region. ASAPROSAR promotoras, working in 15 rural communities, hosted oral health and nutrition camps with Ministry of Health dentists 1-2 times per year from July 2006 through July 2010, where they provided nutrition and oral health education, free-of-cost dental examinations, referral to further treatment, fluoride varnish applications, toothbrushes, and fluoride toothpaste. At these camps, promotoras verbally explained the study details and invited all families with children 6 months through 6 years of age to participate in the study. Children below the age of 6 months, and at or above the age of 6 years were excluded from the study population but were given nutrition and oral health education. Mothers provided their signature or thumbprint as written informed consent for their own and their child's participation. Children provided verbal assent to participate according to their developmental ability. The study was approved by the University of California, Berkeley's Institutional Review Board (\#2010-06-1655) and ASAPROSAR directorship.

\subsection{Data Collection}

Data collected consisted of (1) the mother's interview, (2) child anthropometric measures (height and weight), and (3) child dental examination. The survey tool (Supplementary Materials, File S1) was adapted from the World Health Organization (WHO) Oral Health Surveys and included 49 questions on family demographics, oral health knowledge on the causes and consequences of caries, maternal and child nutrition and oral hygiene practices, and the mother's perception of her child's oral and overall health [20]. Surveys 
were conducted in Spanish by trained promotoras and health volunteers. Responses from participating mothers and data from exams were recorded on paper forms and entered into an Excel database.

Children's height and weight, in light clothing and no shoes, were measured using a digital weighing scale and stadiometer by trained volunteers according to WHO anthropometric protocol [21]. Anthropometric data were entered into WHO AnthroPlus software (version 3.2.2) to generate standardized nutrition Z-scores, including weight-for-age Zscore (WAZ), height-for-age Z-score (HAZ), and weight-for-height Z-score (WHZ) [22]. Trained and licensed Salvadoran and U.S. dentists conducted a dental exam for each child, with headlamps and mirrors. No formal calibration procedures were undertaken. However, the dentists standardized their processes for examination by establishing an agreement on diagnostic criteria prior to data collection. During examinations, dentists were positioned side-by-side so that further comparison was possible and to reduce inter-examiner variability. If any unclear findings were present, examiners collaborated with one another to collectively decide upon the classification of a lesion. From each child's dental exam, the presence of ECC was identified by the presence of one or more decayed (d), missing due to caries (m), or filled (f) primary teeth (t) [20]. For each child, the summed total number of decayed, missing, and filled teeth recorded was used as their "dmft score".

\subsection{Statistical Analysis}

Data were de-identified, cleaned, and analyzed on RStudio (version 1.0.143, RStudio PBC, Boston, MA, USA). The final study sample included baseline mother-child pair visits from 2006 to 2010; repeat visits over the years were excluded from the analysis to reduce intervention effects. Descriptive statistics were then generated to characterize the study population. Two different logistic regression models were built to examine nutrition and dental caries outcomes.

The first model utilized ordinal logistic regression to identify risk factors for child undernutrition by examining ordinal weight-for-age Z-scores. Prior studies on undernutrition have typically used a binary outcome of "developed undernutrition" (WAZ, HAZ, or WHZ $\leq-2.0$ ) and "did not develop undernutrition" (WAZ, HAZ, or WHZ > -2.0) [23,24]. In order to highlight more upstream factors that can influence a child's risk for developing undernutrition, this analysis considers 3 outcomes: "developed undernutrition" (WAZ $\leq-2.0 \mathrm{Z}$-score), "at risk for undernutrition" $(-2.0<$ WAZ-score $\leq-1.0)$, and "did not develop undernutrition" (>-1.0 WAZ-score). Independent variables for the final multivariate model were selected based on a literature review that identified factors associated with undernutrition. Goodness of fit and the proportional odds assumption were assessed for the final model using the Lipsitz test and the Brant test, respectively $[25,26]$.

The second model to identify risk factors for developing sECC utilized binary logistic regression; sECC was defined based on the total number of decayed, missing, or filled teeth (dmft) relative to the child's age group: $\mathrm{dmft} \geq 1 \mathrm{in}$ children under age $3, \mathrm{dmft} \geq 4$ at age 3 , $\mathrm{dmft} \geq 5$ at age 4 , and $\mathrm{dmft} \geq 6$ at age 5 [11]. Similar to the first model, covariates were selected based on factors associated with poor oral health found in existing literature. The Hosmer-Lemeshow method was used to test the model for goodness of fit, using a threshold of $\alpha<0.05$ to establish statistical significance for all analyses [25].

\section{Results}

The final cross-sectional analysis sample included baseline data from a total of 797 participating mother-child pairs from 2006 through 2010. Of these, approximately $21 \%$ were recruited in year 1, 26\% were recruited in year 2, 16\% were recruited in year 3, 15\% were recruited in year 4 , and $22 \%$ were recruited in year 5 of the program.

\subsection{Demographic Characteristics}

Table 1 shows the baseline demographics of the participating mothers and children. The mothers' mean age was 29 years, and the children's mean age was 2.9 years. Most 
mothers (58.2\%) had some primary school level education, while $12.0 \%$ had no formal education and $29.8 \%$ had 8 years of schooling or more. The average household size consisted of 5-6 people. Slightly more than half (56.2\%) of families had potable drinking water at home. Most families had electric lighting available at home $(84.4 \%)$ and used some sort of wood fuel for cooking (86.8\%).

Table 1. Mother-child participant demographics.

\begin{tabular}{|c|c|}
\hline Participant Demographics ( $n$ Total Respondents) & $n(\%)$ or Mean \pm s.d. \\
\hline \multicolumn{2}{|l|}{ Mother and Family Characteristics } \\
\hline Mother's Age (years) $(n=591)$ & $29.0 \pm 8.9$ \\
\hline Formal Education (mean) $(n=574)$ & $5.6 \pm 3.8$ \\
\hline \multicolumn{2}{|l|}{ Formal Education (years) $(n=574)$} \\
\hline 0 & $12.0 \%$ \\
\hline $1-3$ & $19.3 \%$ \\
\hline $4-7$ & $38.9 \%$ \\
\hline $8+$ & $29.8 \%$ \\
\hline Family Size (mean) $(n=582)$ & $5.5 \pm 2.4$ \\
\hline \multicolumn{2}{|l|}{ Family Size $(n)(n=582)$} \\
\hline $2-4$ & $18.2 \%$ \\
\hline $5-7$ & $64.4 \%$ \\
\hline $8+$ & $17.4 \%$ \\
\hline Potable Water at Home $(n=589)$ & $56.2 \%$ \\
\hline Electric Lighting at Home $(n=590)$ & $84.4 \%$ \\
\hline \multicolumn{2}{|l|}{ Cooking Fuel Source $(n=590)$} \\
\hline Wood Only & $27.9 \%$ \\
\hline Gas Only & $13.2 \%$ \\
\hline Both Wood and Gas & $58.9 \%$ \\
\hline Caregivers Receiving Prenatal Care $(n=797)$ & $91.7 \%$ \\
\hline Children with Completed Vaccinations $(n=797)$ & $94.8 \%$ \\
\hline Children who Visited Dentist At least Once $(n=796)$ & $16.6 \%$ \\
\hline \multicolumn{2}{|l|}{ Child Characteristics $(n=797)$} \\
\hline Age (mean) & $2.9 \pm 1.6$ \\
\hline \multicolumn{2}{|l|}{ Age (years) } \\
\hline$(0.5-1]$ & $12.3 \%$ \\
\hline$(1-2]$ & $22.5 \%$ \\
\hline$(2-3]$ & $20.1 \%$ \\
\hline$(3-4]$ & $13.0 \%$ \\
\hline$(4-5]$ & $14.9 \%$ \\
\hline$(5-6]$ & $17.1 \%$ \\
\hline \multicolumn{2}{|l|}{ Sex } \\
\hline Male & $51.1 \%$ \\
\hline Female & $48.9 \%$ \\
\hline
\end{tabular}

\subsection{Child Dietary Habits and Maternal Health Knowledge}

Table 2 reports children's caries-related dietary patterns and mothers' oral health knowledge and perceptions. While $94.3 \%$ of children were ever breastfed (any attempt at breastfeeding, even if only for a short time), nearly one-half (42.6\%) of children were also bottle-fed (mixed feeding). On average, children in this population were breastfed for 17.2 months; although the mean duration of bottle feeding was approximately 2 years (24.7 months), some children bottle fed until 4.5 years of age. One-third (33.3\%) of the mothers reported that their children frequently drank from the baby bottle as they went to bed. Among bottle-fed children, the most common baby bottle contents were milk $(80.2 \%)$, but approximately 3 in 4 children (73.0\%) were given sugar-sweetened beverages (SSBs) in the baby bottle. SSBs reported in the baby bottle included sweetened incaparina: a commercial, fortified grain-based gruel powder $(33.6 \%)$, juice with sugar $(28.9 \%)$, lemonade with sugar $(28.4 \%)$, sugar water $(17.1 \%)$, soda $(12.9 \%)$, and coffee with sugar $(9.9 \%)$. Approximately half of children $(54.4 \%)$ drank milk daily. Approximately one-third of children consumed 
candy/sweets (33.4\%) and soda (35.4\%) weekly, and more children ate candy/sweets at least once daily $(22.2 \%)$ compared to soda $(6.2 \%)$.

While a sizable portion of mothers reported knowing that not brushing teeth frequently $(63.2 \%)$ and eating candy/sweets (29.6\%) caused dental caries, far fewer mentioned that soda/juice $(15.1 \%)$ or that using the baby bottle $(12.9 \%)$ can cause caries. Most mothers noted that caries can negatively impact a child's ability to eat $(88.5 \%)$ and can cause mouth pain (53.2\%); however, very few mothers reported knowing that caries could impact children's quality of sleep $(10.8 \%)$ or that caries were detrimental for their overall health (5.3\%). Approximately one-quarter of mothers assessed their children's oral health as "bad" for both oral health $(25.8 \%)$ and overall health $(26.2 \%)$.

Table 2. Children's caries-related nutritional practice responses and mothers' health knowledge and perceptions.

\begin{tabular}{|c|c|}
\hline Nutrition/Oral Health Metric ( $n$ Total Respondents) & $n(\%)$ or Mean \pm s.d. \\
\hline \multicolumn{2}{|l|}{ Child Nutrition Practices $(n=793)$} \\
\hline Ever breastfed & $94.3 \%$ \\
\hline Mean breastfeeding duration (months) & $17.2 \pm 8.6$ \\
\hline Range breastfeeding duration (months) & $1-52$ \\
\hline Ever bottle-fed & $45.8 \%$ \\
\hline Mixed bottle-fed and breastfed & $42.6 \%$ \\
\hline Mean bottle-feeding duration (months) & $24.7 \pm 12.7$ \\
\hline Range bottle-feeding duration (months) & $1-54$ \\
\hline Bottle for sleeping ${ }^{1}$ & $33.3 \%$ \\
\hline \multicolumn{2}{|l|}{ Baby bottle contents 1,2} \\
\hline $\mathrm{SSBs}^{3}$ in the bottle & $73.0 \%$ \\
\hline Milk & $80.2 \%$ \\
\hline Incaparina 4 & $33.6 \%$ \\
\hline Juice with sugar & $28.9 \%$ \\
\hline Lemonade & $28.4 \%$ \\
\hline Sugar water & $17.1 \%$ \\
\hline Soda & $12.9 \%$ \\
\hline Baby milk formula & $9.9 \%$ \\
\hline Coffee with sugar & $9.9 \%$ \\
\hline \multicolumn{2}{|l|}{ Children's Frequency of Consumption ${ }^{1}$} \\
\hline \multicolumn{2}{|l|}{ Milk $(n=777)$} \\
\hline Infrequently (never or rarely) & $30.4 \%$ \\
\hline Weekly & $15.1 \%$ \\
\hline Daily & $54.4 \%$ \\
\hline \multicolumn{2}{|l|}{ Soda/juice $(n=799)$} \\
\hline Infrequently (never or rarely) & $58.4 \%$ \\
\hline Weekly & $35.4 \%$ \\
\hline Daily & $6.2 \%$ \\
\hline \multicolumn{2}{|l|}{ Candy/sweets $(n=784)$} \\
\hline Infrequently (never or rarely) & $44.4 \%$ \\
\hline Weekly & $33.4 \%$ \\
\hline Daily & $22.2 \%$ \\
\hline \multicolumn{2}{|l|}{ Maternal Oral Health Knowledge ${ }^{1}$} \\
\hline \multicolumn{2}{|l|}{ Causes of caries $(n=591)$} \\
\hline Not brushing frequently & $63.2 \%$ \\
\hline Candy/sweets & $29.6 \%$ \\
\hline Soda/juice & $15.1 \%$ \\
\hline Baby bottle & $12.9 \%$ \\
\hline \multicolumn{2}{|l|}{ Consequences of caries $(n=590)$} \\
\hline Trouble eating & $88.5 \%$ \\
\hline Mouth pain & $53.2 \%$ \\
\hline Rotting teeth & $39.8 \%$ \\
\hline Problems sleeping & $10.8 \%$ \\
\hline Poor overall health & $5.3 \%$ \\
\hline
\end{tabular}


Table 2. Cont.

\begin{tabular}{cc}
\hline Nutrition/Oral Health Metric ( $\boldsymbol{n}$ Total Respondents) & $\boldsymbol{n}$ (\%) or Mean \pm s.d. \\
\hline Maternal Perception of Children's Health & \\
Mother's opinion of their child's teeth $(n=771)$ & $38.9 \%$ \\
Excellent & $35.3 \%$ \\
Okay & $25.8 \%$ \\
Bad & $36.8 \%$ \\
Mother's opinion of their child's overall health $(n=784)$ & $36.9 \%$ \\
Excellent & $26.2 \%$ \\
Okay & \\
\hline
\end{tabular}

${ }^{1}$ The open-ended question format allowed for multiple responses, and percentages reported indicate the percent $(\%)$ of mothers responding, not the $\%$ of responses; ${ }^{2}$ Contents of the baby bottle were calculated by using only the 363 participants who bottle-fed their children in the denominator; ${ }^{3}$ SSB: sugar-sweetened beverage; ${ }^{4}$ Incaparina is a commercial, fortified grain-based gruel powder.

\subsection{Child Oral Health and Nutritional Status}

Table 3 summarizes the nutritional and oral health status of participating children. While only $10.4 \%$ of the children experienced either moderate or severe undernutrition (WAZ $\leq-2)$, approximately one-fourth $(24.1 \%)$ were at risk for undernutrition. The majority of children $(65.4 \%)$ did not experience undernutrition, including $5.2 \%$ who were overweight or obese. Regarding oral health status, approximately half (47.4\%) of children exhibited ECC. While 1 in 6 children experienced a dmft score between 1-3 (16.1\%), 1 in 3 children (31.3\%) had 4 or more decayed teeth, with a range up to 16 decayed teeth (i.e., decay in over $\frac{3}{4}$ of their total baby/primary teeth). One-third (31.0\%) of the children experienced sECC. Almost all tooth decay (97.3\%) was untreated, and approximately 1 in 5 children $(19.3 \%)$ in this population experienced mouth pain.

Table 3. Children's nutritional and oral health status $(n=797)$.

\begin{tabular}{|c|c|}
\hline Descriptive Variable & $n(\%)$ or Mean \pm s.d. \\
\hline \multicolumn{2}{|l|}{ Nutritional Status } \\
\hline Moderate or severe undernutrition $(\text { WAZ } \leq-2.0)^{1}$ & $10.4 \%$ \\
\hline At risk for developing undernutrition $(\mathrm{WAZ} \leq-1.0)^{1}$ & $24.1 \%$ \\
\hline Did not develop undernutrition (WAZ $>-1.0)^{1}$ & $65.4 \%$ \\
\hline Overweight or obese $(\mathrm{WAZ}>2.0)^{1}$ & $5.2 \%$ \\
\hline Mean WAZ score ${ }^{1}$ & $-0.6 \pm 1.2$ \\
\hline Mean HAZ score ${ }^{2}$ & $-1.3 \pm 1.2$ \\
\hline Mean WHZ score ${ }^{3}$ & $-0.1 \pm 1.3$ \\
\hline \multicolumn{2}{|l|}{ Oral Health Status } \\
\hline Early childhood caries (ECC) & $47.4 \%$ \\
\hline Severe early childhood caries (sECC) & $31.0 \%$ \\
\hline Mean number of decayed teeth (dmft) ${ }^{4}$ & $2.8 \pm 3.9$ \\
\hline Range number of decayed teeth & 16 \\
\hline $\mathrm{dmft} 1-3$ & $16.1 \%$ \\
\hline $\mathrm{dmft} 4-6$ & $13.9 \%$ \\
\hline dmft 7-9 & $8.4 \%$ \\
\hline $\operatorname{dmft} 10+$ & $9.0 \%$ \\
\hline Untreated tooth decay & $97.3 \%$ \\
\hline Reported mouth pain & $19.3 \%$ \\
\hline
\end{tabular}

${ }^{1}$ WAZ: weight-for-age z-score; ${ }^{2} \mathrm{HAZ}$ : height-for-age z-score; ${ }^{3}$ WHZ: weight-for-height z-score; ${ }^{4} \mathrm{dmft}$ : decayed, missing, or filled teeth.

\subsection{Risk Factors for Child Underweight}

After adjusting for covariates on socioeconomic demographics, the final multivariable model identified three factors was significantly associated with increased odds of being more underweight (i.e., either at risk of underweight or currently underweight). Children 
fed from baby bottles with SSBs had 2.26 times increased odds of being more underweight compared to those who were not fed SSBs in the baby bottle (OR: 2.26, 95\% CI: 1.32-3.82). Higher numbers of decayed teeth ( $\mathrm{dmft}$ scores) were also significantly associated with increased odds for being underweight; an additional dmft unit corresponded with 1.05 times increased odds (OR 1.05, 95\% CI: 1.01-1.09). Living in a household that used wood-only fuel for cooking was also significantly associated with 1.60 times increased odds of being underweight compared to those from households that used gas only or a mix of wood and gas (OR 1.60, 95\% CI: 1.14-2.23) (See Table 4 for detailed model results.). Full models were compared to nested models using the likelihood ratio test, and model goodness of fit was assessed using the Lipsitz test [25]. The proportional odds assumption was also satisfied for the final model $(p=0.39)$ [26]. Based on the results, the null hypothesis that ordinal logistic regression is a good fit for the sample population was not rejected $(p=0.19)$, and instead, it was concluded that the final model was a good fit for this population.

Table 4. Risk factors for child underweight (low WAZ) ${ }^{1}$ outcome $(n=563)$.

\begin{tabular}{|c|c|c|c|c|c|}
\hline Co-Variates & $\mathrm{B}^{2}$ & $\mathrm{SE}^{3}$ & $\mathrm{OR}^{4}$ & $95 \% \mathrm{CI}^{5}$ & $p$-Value \\
\hline $\begin{array}{l}\text { Intercept }{ }^{\mathrm{a}} \text { : Did not develop } \\
\text { undernutrition I At risk for } \\
\text { undernutrition }\end{array}$ & 0.87 & 0.30 & - & - & 0.003 \\
\hline $\begin{array}{c}\text { Intercept }{ }^{\mathrm{b}} \text { : At risk for } \\
\text { undernutrition I Developed } \\
\text { undernutrition } \\
\mathrm{SSB}^{6} \text { in baby bottle }\end{array}$ & 2.41 & 0.32 & - & - & 0.000 \\
\hline $\begin{array}{c}\text { Reference: No SSB used } \\
\text { SSB Used }\end{array}$ & 0.81 & 0.32 & 2.26 & $1.32-3.82$ & 0.011 \\
\hline $\begin{array}{l}\text { Number of } \mathrm{dmft}^{7} \\
\text { Cooking fuel source }\end{array}$ & 0.05 & 0.02 & 1.05 & $1.01-1.09$ & 0.023 \\
\hline Reference: Both gas and wood & 0.25 & 0.26 & 1.28 & $0.82-1.97$ & 0.349 \\
\hline $\begin{array}{c}\text { Gas only } \\
\text { Wood only } \\
\text { Child sex }\end{array}$ & 0.46 & 0.20 & 1.60 & $1.14-2.23$ & 0.022 \\
\hline $\begin{array}{c}\text { Reference: Female } \\
\text { Male }\end{array}$ & 0.13 & 0.18 & 1.13 & $0.85-1.52$ & 0.479 \\
\hline $\begin{array}{c}\text { Maternal education level } \\
\text { Reference: No formal education } \\
1-7 \text { years } \\
\text { 8+ years }\end{array}$ & $\begin{array}{l}-0.22 \\
-0.13\end{array}$ & $\begin{array}{l}0.28 \\
0.33\end{array}$ & $\begin{array}{l}0.81 \\
0.88\end{array}$ & $\begin{array}{l}0.52-1.28 \\
0.51-1.52\end{array}$ & $\begin{array}{l}0.442 \\
0.700\end{array}$ \\
\hline $\begin{array}{l}\text { Brant test for proportional odds asst } \\
\text { goodness-of-fit of the overall model: } \\
\text { weight-for-age z-score; }{ }^{2} \mathrm{~B} \text { : Coefficien } \\
\text { SSB: sugar-sweetened beverage; }{ }^{7} \mathrm{dr} \\
b<0.05 \text {. a Brant test for proportional o } \\
\text { of goodness-of-fit of the overall model }\end{array}$ & $\begin{array}{l}\text { on: C } \\
\text { nood } \\
\text { e; }{ }^{3} \mathrm{SI} \\
\text { ecaye } \\
\text { sump }\end{array}$ & 5 & $\begin{array}{l}7, \text { an } \\
.49, \mathrm{c} \\
\text { Odd } \\
\text { th. N } \\
\text { df }=\end{array}$ & $\begin{array}{l}\text { ue }=0.39 \\
\text { nd } p \text {-valu } \\
{ }^{5} \text { CI: Cor } \\
\text { ld values } \\
\text {-value }=0\end{array}$ & $\begin{array}{l}\text { psitz te } \\
.19 .{ }^{1} \mathrm{~V} \\
\text { nce Inte } \\
\text { ignifica } \\
\text { Lipsitz }\end{array}$ \\
\hline
\end{tabular}

\subsection{Risk Factors for Child Severe Caries Outcomes}

Controlling for socioeconomic demographic covariates, this final multivariable model identified two factors significantly associated with increased odds of sECC. A unit increase in age was significantly associated with 1.57 increased odds of sECC (OR 1.57, 95\% CI: 1.42-1.74). Children who were bottle-fed with SSBs in the baby bottle also had 1.53 times significantly higher odds of sECC compared to children that did not have SSBs in their baby bottle (OR 1.53, 95\% CI: 1.07-2.18). Model fit was assessed using the Hosmer-Lemeshow test. Based on the results, the null hypothesis was unable to be rejected and there was no evidence that this model was a poor fit for the data $(p=0.11)$ [26] (See Table 5 for detailed model results). 
Table 5. Risk factors for severe early childhood caries (sECC) outcome $(n=572)$.

\begin{tabular}{|c|c|c|c|c|c|}
\hline Co-Variates & $\mathbf{B}^{1}$ & $\mathrm{SE}^{2}$ & $\mathrm{OR}^{3}$ & $95 \% \mathrm{CI}^{4}$ & $p$-Value \\
\hline $\begin{array}{l}\text { Intercept: No sECC I sECC } \\
\text { SSB }^{5} \text { in baby bottle }\end{array}$ & -3.09 & 0.52 & - & - & 0.000 \\
\hline $\begin{array}{l}\text { Reference: No SSB used } \\
\text { SSB Used }\end{array}$ & 0.43 & 0.21 & 1.53 & $1.07-2.18$ & 0.047 \\
\hline $\begin{array}{l}\text { Child age (continuous) } \\
\text { Maternal education level }\end{array}$ & 0.45 & 0.06 & 1.57 & $1.42-1.74$ & 0.000 \\
\hline Reference: No formal education & 0.34 & 0.34 & 1.41 & $0.81-2.51$ & 0.312 \\
\hline $\begin{array}{l}1-7 \text { years } \\
8+\text { years }\end{array}$ & 0.11 & 0.40 & 1.11 & $0.58-2.18$ & 0.783 \\
\hline Cooking fuel source & & & & & \\
\hline $\begin{array}{l}\text { Reference: Both gas and wood } \\
\text { Gas only }\end{array}$ & $\begin{array}{l}-0.34 \\
0.02\end{array}$ & $\begin{array}{l}0.31 \\
0.26\end{array}$ & $\begin{array}{l}0.71 \\
1.02\end{array}$ & $\begin{array}{l}0.42-1.16 \\
0.67-1.56\end{array}$ & $\begin{array}{l}0.262 \\
0.933\end{array}$ \\
\hline $\begin{array}{l}\text { Wood only } \\
\text { Child sex }\end{array}$ & & & & & \\
\hline $\begin{array}{c}\text { Reference: Female } \\
\text { Male }\end{array}$ & -0.34 & 0.20 & 0.71 & $0.51-0.99$ & 0.091 \\
\hline $\begin{array}{c}\text { In-home electric lighting } \\
\text { Reference: Not available } \\
\text { Available }\end{array}$ & 0.52 & 0.33 & 1.68 & $0.99-2.91$ & 0.114 \\
\hline $\begin{array}{c}\text { Running potable water } \\
\text { Reference: Not available } \\
\text { Available }\end{array}$ & 0.26 & 0.22 & 1.30 & $0.92-1.86$ & 0.219 \\
\hline
\end{tabular}

Hosmer-Lemeshow goodness-of-fit of the overall model: Chi-square $=14.47, \mathrm{df}=9$, and $p$-value $=0.11 ;{ }^{1} \mathrm{~B}$ Coefficient Value; ${ }^{2}$ SE: Standard Error; ${ }^{3}$ OR: Odds Ratio; ${ }^{4}$ CI: Confidence Interval; ${ }^{5}$ SSB: sugar-sweetened beverage. Note: bold values are significant at $p<0.05$.

ASAPROSAR promotoras also prepared a supplemental child case study illustrating the relationships among baby bottle use, sECC, and malnutrition (Appendix A).

\section{Discussion}

This study identifies factors for developing risk of undernutrition, moderate to severe undernutrition, and severe early childhood caries in a convenience sample of 797 children ages 6 months to 6 years in rural Salvadoran communities. Findings from this analysis highlight the interrelationship of children's dietary consumption and their nutrition and oral health status. Specifically, consumption of SSBs in the baby bottle was significantly associated with undernutrition risk, severe to moderate undernutrition, and tooth decay. This study also found that tooth decay was significantly associated with both being at risk for undernutrition and with developing undernutrition. This study's findings are consistent with existing literature, particularly regarding the consequences of the global nutrition transition in Latin America and other developing regions [27-29].

\subsection{Sugar-Sweetened Beverages (SSBs), Bottle Feeding, and Adverse Health Outcomes}

Past research has demonstrated the association between bottle-feeding, SSBs, and sweet snacks with ECC, which was formerly called "baby bottle tooth decay" [30-32]. Other studies have also identified a relationship between ECC and undernutrition, particularly in low- and middle-income countries [7], as well as associations of ECC with obesity, typically in higher-income populations [33]. In this study, sugar-sweetened beverages for bottlefeeding was significantly associated with undernutrition outcomes and sECC. While most children were breastfed, nearly half of the children were also bottle-fed, the majority were fed sugar-sweetened beverages in the baby bottle, half of children were given the bottle in bed, and some children were given the baby bottle until nearly age 5-all of which have previously been shown to contribute to sECC [27]. Though mothers were largely familiar with common causes of dental caries, most were unaware of the relationship between caries and sugar-sweetened beverages, especially when used for prolonged periods in the baby bottle. This study extends the current dialogue on the adverse nutritional consequences 
of sugar-sweetened beverages by identifying consumption in the baby bottle as a risk factor for developing undernutrition (lower WAZ scores), whereas most studies have cited the risk for obesity [34]. This study's findings also highlight the increased importance of healthy bottle-feeding practices, as women globally transition to leaving the home for work and switching to bottle-feeding [35]. Frequent consumption of sugary drinks might contribute to undernutrition through suppressing children's appetite for nutritious foods [36]. There are multiple possible physiological pathways: undernutrition can arise from sECC causing chronic infection/inflammation and mouth pain that can interfere with appetite and chewing ability, and chronic infection/inflammation can cause dysregulation of hepcidin and the hypothalamic-pituitary-adrenal hormonal axis.

\subsection{Association between Early Childhood Caries (ECC) and Undernutrition}

This study demonstrates an important relationship between children's oral health and nutrition status. Half of the children were found to have ECC, one-third had severe ECC, and severe ECC was a significant risk factor for developing risk for undernutrition as well as moderate to severe undernutrition (OR 1.05). These findings show that, for each additional decayed tooth, a child has a $5 \%$ increased risk of undernutrition. While the mean number of decayed teeth (dmft) in this study was approximately 3 teeth, $31.4 \%$ of children had higher numbers of decayed teeth, up to 16 decayed teeth out of a total 20 baby/primary teeth - a sizable proportion of children with high numbers of decayed teeth who are at substantial additional risk for undernutrition.

\subsection{Demographics and Socioeconomic Determinants}

In this study, household use of wood fuel for cooking was a key risk factor for developing undernutrition in rural El Salvador. Prior studies have found that cooking with wood fuel is indicative of living in lower-resource settings or in low-GDP countries [37,38]. This finding underscores the need for health interventions to improve the social determinants of health and to reduce economic and health disparities [39]. Other demographic characteristics such as mother's education and family size were not significantly associated with undernutrition or sECC. Our finding that mothers' oral health knowledge was not significantly associated with children's nutrition or oral health outcomes may be indicative of structural health barriers-such as, but not limited to, the lack of affordable nutritious foods and limited access to healthcare in rural areas-to ensuring good nutrition and oral health in rural El Salvador [18].

\subsection{Recommendations}

The shared set of risk factors between the two models in this study-for undernutrition and for ECC - also supports advocacy for more coordinated oral health and maternal-child health and nutrition programs, starting from pregnancy and birth onward. Maternal-child health professionals and promotoras should continue to promote breastfeeding, with clear guidelines for bottle-feeding when needed (including feeding babies only breastmilk or formula (not sugar-sweetened liquids) in the baby bottle, not putting the baby to bed with the bottle, and stopping the bottle after 12 months of age) [11]. This recommendation builds upon the Pan American Health Organization's (PAHO) existing strategies for promoting healthy breastfeeding practices as part of their childhood obesity prevention efforts [40]. Maternal child-health interventions should also incorporate promotion of daily child toothbrushing with fluoride toothpaste starting at eruption of the first teeth around 6 months and that parents/caregivers assist children in brushing thoroughly until ages 6-8 [11,41]. In addition, maternal-child health programs should incorporate dental screening, oral health education, preventive fluoride varnish treatments, and referral to dental treatment as needed at well-child visits starting in infancy onward, as promoted by PAHO's program Salud Oral Factores de Riesgo (SOFAR) [41,42].

Since 2008, the SOFAR initiative has trained cross-disciplinary health professionals - physicians, nutritionists, dentists, and social workers (among others) - to integrate oral 
health prevention with strategies for general health promotion by emphasizing evidence of shared risk factors. SOFAR advocates for coordinated, early interventions for pediatric populations through incorporating preventive oral health strategies (applying fluoride varnish and promoting oral health practices to parents) at regular primary care appointments for children [42]. Recent research has shown effectiveness in lowering pediatric oral disease through implementing integrated, interprofessional approaches [43].

Beyond further integration of maternal-child health and nutrition with oral health interventions, these findings also support a socioecological approach for developing interventions at multiple levels-in the home, community, national, and international landscapesthat address the socioeconomic and environmental factors influencing development of child undernutrition and SECC in rural El Salvador [44]. Past literature has indicated that the food environment at and surrounding schools is especially important for protecting children's health [45]. Currently, all Latin American countries have agreed to a set of measures promoted by WHO and PAHO to prevent child obesity, including improving school food environments by strictly regulating labeling and advertising of processed snacks and beverages [40]. In June 2017, the Ministry of Education in El Salvador created a set of nutritional criteria to reduce children's access to unhealthy beverages and foods high in sugar, fat, and salt in schools [46]. However, better enforcement of the policy is needed. Prior research has noted that effective implementation of school-based obesity-prevention programs suffers when there is limited integration of the children's families and school vendors in the program's efforts [47]. Additional policies are still needed to limit children's access to unhealthy foods and beverages sold by vendors near the school grounds $[18,45]$. This can be supported by encouraging community access to fresh produce and by drafting additional restrictions for the marketing of fast foods and SSBs-a driver of the nutrition transition in Latin America [18,45,48,49]. The feasibility of public health interventions in El Salvador is also limited by the presence of context-specific challenges, including gang violence threatening implementation of sustainable development, high vulnerability to natural disasters severely impacting infrastructure and agriculture, and limited integration of national health systems [50]. Further research is also needed to assess the impact of community health programs on underserved communities and to foster a community-based participatory research model in which local stakeholders are engaged in the design and implementation of effective health interventions [51].

\subsection{Study Limitations and Strengths}

The limitations of this study include convenience sampling, which limits the generalizability of findings. The cross-sectional study design is unable to establish causal relationships between risk factors and outcomes. Survey responses may be affected by recall and respondent biases. Due to time limitations in the mother interviews, the dietary consumption questions only included key cariogenic foods and drinks rather than a more comprehensive 24-h diet recall. Undernutrition outcomes could also have been more accurately modeled had the survey captured details on consumption of healthy foods, child infectious disease history, maternal malnutrition history and practices, and micronutrient deficiency [52]. As the study found wood-fuel cooking as a significant sociodemographic risk factor for developing undernutrition, the results interpret wood-fuel cooking as a proxy for low economic status. This interpretation is potentially limited by the proportion of families using wood fuel and differs from more conventional methods of using household assets to estimate income levels, which may have more accurately controlled for socioeconomic confounders in this analysis.

The study strengths are that the physical examination of children's nutritional and oral health status in combination with the survey, including demographics, diet, practices, and perceptions, facilitated analysis of many associated risk factors for child nutrition and oral health outcomes. This study also builds upon existing literature by applying the ordinal logistic model to identify key risk factors for populations at risk for developing undernutrition. These findings can better guide early childhood health interventions to 
help mitigate risk for undernutrition and to prevent development of moderate to severe undernutrition. Longitudinal studies with a cohort representative of the population and additional research on the effectiveness of interventions to reduce consumption of SSBs in the baby bottle for the prevention of child undernutrition and SECC could build on these findings.

\section{Conclusions}

This study demonstrated the adverse impacts of the global nutrition transition on the nutritional status of a sample of young children in rural El Salvador. High rates of feeding young children sugar-sweetened beverages in the baby bottle were associated with increased risk for developing undernutrition and early childhood caries, and early childhood caries was further associated as a risk factor for undernutrition. To improve child nutrition, maternal-child health and nutrition programs should work with oral health programs to discourage feeding children sugar-sweetened beverages in the baby bottle, should advocate for policies to limit the marketing of sugar-sweetened beverages to children and families, and should ensure oral health screening and care for young children at well-child visits from infancy onward. Future research is needed to design more effective and sustainable community health programs to mitigate the consequences of the global nutrition transition.

Supplementary Materials: The following are available online at https:/ / www.mdpi.com/1660-460 1/18/1/260/s1, File S1: Mother-child interview form.

Author Contributions: All authors made significant contributions to the conception or design of the work or to the acquisition, analysis or interpretation of data. Conceptualization, K.S.-G.; data curation, K.S.-G. and L.L.; formal analysis, P.A. and A.B.; investigation, P.A., A.B., B.T., and K.S.-G.; project administration, K.S.-G. and L.L.; resources, K.S.-G. and L.L.; writing-original draft, P.A.; writing-review and editing, P.A., A.B., B.T., L.L., and K.S.-G. All authors have read and agreed to the published version of the manuscript.

Funding: This research was funded by the UC Berkeley Professional Development Fund, UC Berkeley Center for Health Research, Strachan Foundation, Lanterns Projects, and the UC Berkeley Children's Oral Health and Nutrition Program.

Institutional Review Board Statement: The study was conducted according to the guidelines of the Declaration of Helsinki, and approved by the Institutional Review Board of the University of California, Berkeley (\#2010-06-1655).

Informed Consent Statement: Informed consent was obtained from all subjects involved in the study.

Data Availability Statement: The data presented in this study are available upon reasonable request to the corresponding author. The data are not publicly available due to privacy concerns for participants.

Acknowledgments: Deep appreciation to Eduvigas (Vicky) Guzmán, Mirian Gonzalez, Marelen Guerrero, and Caroline Peterson for their longstanding support for children's oral health. We would also like to thank Global Grins, Colgate, Sunstar, and VarnishAmerica for donations of toothbrushes, toothpastes, and fluoride varnish. Publication made possible in part by support from the Berkeley Research Impact Initiative (BRII) sponsored by the UC Berkeley Library.

Conflicts of Interest: The authors declare no conflict of interest. The funders had no role in the design of the study; in the collection, analyses, or interpretation of data; in the writing of the manuscript; or in the decision to publish the results.

\section{Appendix A. Case Study-Bottle-Feeding with Sugary Drinks, Severe Early Childhood Caries, and Malnutrition}

Since 1972, (ASAPROSAR, www.asaprosar.org), a Salvadoran nonprofit, nongovernmental organization, has promoted community health through education and empowerment. A key focus has been training community health workers to work with families from pregnancy through 6 years to promote early childhood health and development through primary health care and developmental stimulation. The promotoras collaborate 
with community leaders and serve as local resources for community education and family guidance on maternal-child health and development.

Since 2004, ASAPROSAR has collaborated with the University of California, Berkeley, School of Public Health to focus on child nutrition and oral health. The collaboration has facilitated training of hundreds of promotoras and community leaders on the harmful effects of ultra-processed snack foods and sugary drinks (especially in the baby bottle) on early childhood oral health, nutrition, and well-being and collaboration with Ministry of Health dentists, community leaders, teachers, and parents to incorporate oral health promotion and caries prevention into child nutrition programs to create a new culture of nutrition and oral health. Promotoras provide oral health and nutrition education for mothers and infants/toddlers during home visits and instituted daily toothbrushing in preschools and community "oral health brigades" with Ministry of Health dentists for dental screening, application of fluoride varnish, and free toothbrushes and fluoride toothpaste for children and family members. In addition, children are referred for dental treatment, as needed, with case management for those with the most severe dental and nutritional needs.

Early in the oral health and nutrition program, a promotora's assessment of a newly enrolled 5-year-old girl, Luz, revealed that she suffered from severe malnutrition. The main risk factors were that she consumed sugary drinks in the baby bottle (pacha), she had decay in half of her baby teeth, and she suffered from frequent mouth pain. The promotora counseled the family on nutrition and sanitation, provided supplemental nutritious snacks, and emphasized the importance of stopping the use of the baby bottle with sugary drinks and of brushing Luz's teeth daily with fluoride toothpaste.

The promotoras discussed this issue in their team meetings and noted that many children were given sugary drinks in the baby bottle up to 5 years of age and suffered from severe dental caries and malnutrition. They said that mothers explained, "My child cries a lot, and it's very difficult to stop the bottle." ASAPROSAR presented the challenge to Luz's community, and they held a parade for the Day of the Child with community leaders, parents, and children, including Luz dressed in a costume of a baby bottle with a sign that said, "No a la pacha". The promotoras also created a character called "La Hada Esperanza", dressed in a fairy costume, whose mission was to exchange baby bottles for a "magic" sippy cup when children turned 1 year of age. During the oral health brigades in every community, Fairy Esperanza educated parents on the dangers of junk food and sugary drinks on children's nutrition and oral health, the importance of offering nutritious foods such as seasonal fruits and vegetables, and proper toothbrushing. At the end of each brigade, Fairy Esperanza invited all families with babies who had turned 1 year to be cheered as they traded their baby bottle for a sippy cup.

In 2017, El Salvador's Legislative Assembly instituted a regulation to prohibit the sale of junk food in schools and health units. Government action helped to sensitize families about the dangers of sugary beverages and snacks, and the importance of promoting the consumption of healthy food to promote child nutrition and health.

Luz stopped drinking from the baby bottle at age 5 . Her family learned to treat her with affection and to stimulate her development. She started to eat and drink more healthfully, began brushing her teeth daily, and received fluoride varnish and dental care. Over the next 1-2 years, Luz gained weight and achieved normal nutritional status. She naturally lost her decayed baby teeth and healthfully maintained her new permanent teeth. Luz is now 18 years old, healthy, and graduated from high school—she is the pride of her community and aspires to be a community leader.

In ASAPROSAR's communities, thousands of other children now have better oral health and nutrition, they no longer suffer from mouth pain, and their development and well-being are improved. Many families are experiencing a new reality where children can grow up healthy and full of hope to build more just and humane communities. 


\section{References}

1. Popkin, B.M.; Adair, L.S.; Ng, S.W. Global Nutrition Transition and the Pandemic of Obesity in Developing Countries. Nutr. Rev. 2012, 70, 3-21. [CrossRef] [PubMed]

2. Gómez, G.; Fisberg, R.M.; Nogueira Previdelli, Á.; Hermes Sales, C.; Kovalskys, I.; Fisberg, M.; Herrera-Cuenca, M.; Cortés Sanabria, L.Y.; García, M.C.Y.; Pareja Torres, R.G.; et al. Diet Quality and Diet Diversity in Eight Latin American Countries: Results from the Latin American Study of Nutrition and Health (ELANS). Nutrients 2019, 11, 1605. [CrossRef] [PubMed]

3. Fact Sheets-Malnutrition. Available online: https://www.who.int/news-room/fact-sheets/detail/malnutrition (accessed on 15 December 2020).

4. World Health Organization. UNICEF-WHO-The World Bank: Joint Child Malnutrition Estimates-Levels and Trends. 2020. Available online: https:/ / www.who.int/nutgrowthdb/estimates/en/ (accessed on 14 April 2020).

5. Vieira, K.A.; Rosa-Júnior, L.S.; Souza, M.A.V.; Santos, N.B.; Florêncio, T.M.M.T.; Bussadori, S.K. Chronic Malnutrition and Oral Health Status in Children Aged 1 to 5 Years: An Observational Study. Medicine 2020, 99, e19595. [CrossRef]

6. Kassebaum, N.J.; Smith, A.G.C.; Bernabé, E.; Fleming, T.D.; Reynolds, A.E.; Vos, T.; Murray, C.J.L.; Marcenes, W.; GBD 2015 Oral Health Collaborators; Abyu, G.Y.; et al. Global, Regional, and National Prevalence, Incidence, and Disability-Adjusted Life Years for Oral Conditions for 195 Countries, 1990-2015: A Systematic Analysis for the Global Burden of Diseases, Injuries, and Risk Factors. J. Dent. Res. 2017, 96, 380-387. [CrossRef]

7. Tsang, C.; Sokal-Gutierrez, K.; Patel, P.; Lewis, B.; Huang, D.; Ronsin, K.; Baral, A.; Bhatta, A.; Khadka, N.; Barkan, H.; et al. Early Childhood Oral Health and Nutrition in Urban and Rural Nepal. Int. J. Environ. Res. Public Health 2019, 16, 2456. [CrossRef] [PubMed]

8. Tinanoff, N.; Baez, R.J.; Diaz Guillory, C.; Donly, K.J.; Feldens, C.A.; McGrath, C.; Phantumvanit, P.; Pitts, N.B.; Seow, W.K.; Sharkov, N.; et al. Early Childhood Caries Epidemiology, Aetiology, Risk Assessment, Societal Burden, Management, Education, and Policy: Global Perspective. Int. J. Paediatr. Dent. 2019, 29, 238-248. [CrossRef] [PubMed]

9. Dülgergil, Ç.; Dalli, M.; Hamidi, M.; Çolak, H. Early Childhood Caries Update: A Review of Causes, Diagnoses, and Treatments. J. Nat. Sci. Biol. Med. 2013, 4, 29. [CrossRef] [PubMed]

10. World Health Organization. Ending Childhood Dental Caries: WHO Implementation Manual. 2020. Available online: https://www.who.int/publications/i/item/ending-childhood-dental-caries-who-implementation-manual (accessed on 1 February 2020).

11. American Association of Pediatric Dentists. Policy on Early Childhood Caries (ECC): Classifications, Consequences, and Preventive Strategies. 2016. Available online: https:/ / www.aapd.org/research/oral-health-policies--recommendations/earlychildhood-caries-classifications-consequences-and-preventive-strategies/ (accessed on 29 August 2020).

12. Sheiham, A.; James, W. Diet and Dental Caries: The Pivotal Role of Free Sugars Reemphasized. J. Dent. Res. 2015, 94, 1341-1347. [CrossRef] [PubMed]

13. Dimaisip-Nabuab, J.; Duijster, D.; Benzian, H.; Heinrich-Weltzien, R.; Homsavath, A.; Monse, B.; Sithan, H.; Stauf, N.; Susilawati, S.; Kromeyer-Hauschild, K. Nutritional Status, Dental Caries and Tooth Eruption in Children: A Longitudinal Study in Cambodia, Indonesia and Lao PDR. BMC Pediatr. 2018, 18, 300. [CrossRef]

14. World Food Programme. El Costo de la Doble Carga de la Malnutrición. Impacto Social y Económico en El Salvador. 2019. Available online: https:/ / es.wfp.org/publicaciones/el-costo-de-la-doble-carga-de-la-malnutricion-el-salvador (accessed on 12 March 2020).

15. World Bank; Shrimpton, R.; Rokx, C. The Double Burden of Malnutrition: A Review of Global Evidence. 2012. Available online: https: / / openknowledge.worldbank.org/handle/10986/27417 (accessed on 12 June 2020).

16. World Food Programme. El Salvador. Available online: https://www.wfp.org/countries/el-salvador (accessed on 12 March 2020).

17. Dabiri, D.; Fontana, M.; Kapila, Y.; Eckert, G.; Sokal-Gutierrez, K. Community-Based Assessment and Intervention for Early Childhood Caries in Rural El Salvador. Int. Dent. J. 2016, 66, 221-228. [CrossRef]

18. Achalu, P.; Zahid, N.; Sherry, D.N.; Chang, A.; Sokal-Gutierrez, K. A Qualitative Study of Child Nutrition and Oral Health in El Salvador. Int. J. Environ. Res. Public Health 2019, 16, 2508. [CrossRef]

19. Conde, W.L.; Monteiro, C.A. Nutrition Transition and Double Burden of Undernutrition and Excess of Weight in Brazil. Am. J. Clin. Nutr. 2014, 100, 1617S-1622S. [CrossRef] [PubMed]

20. World Health Organization. Oral Health Surveys: Basic Methods, 5th ed.; School of Dentistry, University of Sao Paolo: Sao Paolo, Brazil, 2013. Available online: https://www.who.int/oral_health/publications/9789241548649/en/ (accessed on 3 February 2019).

21. World Health Organization. WHO Child Growth Standards: Length/Height-For-Age, Weight-For-Age, Weight-For-Length, WeightFor-Height and Body Mass Index-For-Age; Methods and Development; World Health Organization: Geneva, Switzerland, 2006; ISBN 978-92-4-154693-5.

22. WHO. AnthroPlus for Personal Computers Manual: Software for Assessing Growth of the World's Children and Adolescents; WHO: Geneva, Switzerland, 2009. Available online: http://www.who.int/growthref/tools/en/ (accessed on 20 August 2018).

23. Yu, R.; Wang, Y.; Xiao, Y.; Mo, L.; Liu, A.; Li, D.; Ge, T.; Yu, G.; Zhang, T. Prevalence of Malnutrition and Risk of Undernutrition in Hospitalised Children with Liver Disease. J. Nutr. Sci. 2017, 6, e55. [CrossRef] [PubMed] 
24. Das, S.; Rahman, R.M. Application of Ordinal Logistic Regression Analysis in Determining Risk Factors of Child Malnutrition in Bangladesh. Nutr. J. 2011, 10, 124. [CrossRef] [PubMed]

25. Fagerland, M.W.; Hosmer, D.W. Tests for Goodness of Fit in Ordinal Logistic Regression Models. J. Stat. Comput. 2016, 86, 3398-3418. [CrossRef]

26. Williams, R. Understanding and Interpreting Generalized Ordered Logit Models. J. Math. Sociol. 2016, 40, 7-20. [CrossRef]

27. Branger, B.; Camelot, F.; Droz, D.; Houbiers, B.; Marchalot, A.; Bruel, H.; Laczny, E.; Clement, C. Breastfeeding and Early Childhood Caries. Review of the Literature, Recommendations, and Prevention. Archives de Pédiatrie 2019, 26, 497-503. [CrossRef]

28. Black, R.E.; Victora, C.G.; Walker, S.P.; Bhutta, Z.A.; Christian, P.; de Onis, M.; Ezzati, M.; Grantham-McGregor, S.; Katz, J.; Martorell, R.; et al. Maternal and child undernutrition and overweight in low-income and middle-income countries. Lancet 2013, 382, 427-451. [CrossRef]

29. Moodie, R.; Stuckler, D.; Monteiro, C.; Sheron, N.; Neal, B.; Thamarangsi, T.; Lincoln, P.; Casswell, S.; The Lancet NCD Action Group. Profits and pandemics: Prevention of harmful effects of tobacco, alcohol, and ultra-processed food and drink industries. Lancet 2013, 381, 670-679. [CrossRef]

30. Andrei, K.; Dona, I.D.A.; Cristina, B.; Doriana, A.-F. A Study Concerning Tooth Decay Incidence in Children with Ages Between 3 and 6 Years. ARS Medica Tomitana 2018, 24, 174-178. [CrossRef]

31. Park, S.; Lin, M.; Onufrak, S.; Li, R. Association of Sugar-Sweetened Beverage Intake during Infancy with Dental Caries in 6-Year-Olds. Clin. Nutr. Res. 2015, 4, 9. [CrossRef] [PubMed]

32. Rusali, R.; Najwa Hamali, N.; Muhammad Razi, F.; Mustafa, N.; Asilah Harun, N.; Azwani Mohd Shukri, N. Early Childhood Feeding Practices and Its Association with Early Childhood Caries. J. Food Nutr. Res. 2019, 7, 801-804. [CrossRef]

33. Chen, D.; Zhi, Q.; Zhou, Y.; Tao, Y.; Wu, L.; Lin, H. Association between Dental Caries and BMI in 367 Children: A Systematic Review and Meta-Analysis. Caries Res. 2018, 52, 230-245. [CrossRef] [PubMed]

34. Davis, J.N.; Koleilat, M.; Shearrer, G.E.; Whaley, S.E. Association of Infant Feeding and Dietary Intake on Obesity Prevalence in Low-Income Toddlers: Infant Feeding and Obesity in Hispanics. Obesity 2014, 22, 1103-1111. [CrossRef] [PubMed]

35. Bai, Y.; Wunderlich, S.M. Lactation accommodation in the workplace and duration of exclusive breastfeeding. J. Midwifery Womens Health 2013, 58, 690-696. [CrossRef]

36. Poirier, K.; Totosy de Zepetnek, J.; Bennett, L.; Brett, N.; Boateng, T.; Schwartz, A.; Luhovyy, B.; Bellissimo, N. Effect of Commercially Available Sugar-Sweetened Beverages on Subjective Appetite and Short-Term Food Intake in Boys. Nutrients 2019, 11, 270. [CrossRef]

37. Bonjour, S.; Adair-Rohani, H.; Wolf, J.; Bruce, N.G.; Mehta, S.; Prüss-Ustün, A.; Lahiff, M.; Rehfuess, E.A.; Mishra, V.; Smith, K.R. Solid Fuel Use for Household Cooking: Country and Regional Estimates for 1980-2010. Environ. Health Perspect. 2013, 121, 784-790. [CrossRef]

38. Kayamba, V.; Heimburger, D.C.; Morgan, D.R.; Atadzhanov, M.; Kelly, P. Exposure to Biomass Smoke as a Risk Factor for Oesophageal and Gastric Cancer in Low-Income Populations: A Systematic Review. Mal. Med. J. 2017, 29, 212. [CrossRef]

39. Thornton, R.L.J.; Glover, C.M.; Cené, C.W.; Glik, D.C.; Henderson, J.A.; Williams, D.R. Evaluating Strategies for Reducing Health Disparities by Addressing the Social Determinants of Health. Health Aff. 2016, 35, 1416-1423. [CrossRef]

40. Pan American Health Organization. Plan of Action for the Prevention of Obesity in Children and Adolescents. 2015. Available online: https:/ / www.paho.org/hq/dmdocuments /2015/Obesity-Plan-Of-Action-Child-Eng-2015.pdf?ua=1\&ua=1 (accessed on 13 December 2018).

41. Section on Oral Health. Maintaining and Improving the Oral Health of Young Children. Pediatrics 2014, 134, 1224-1229. [CrossRef]

42. Salud Oral Factores de Riesgo (SOFAR). Available online: https://www.paho.org/sofar/actividades.html (accessed on 2 October 2020).

43. Villena, R.S.; Pesaressi, E.; Frencken, J.E. Reducing Carious Lesions during the First 4 Years of Life: An Interprofessional Approach. J. Am. Dent. Assoc. 2019, 150, 1004-1014. [CrossRef] [PubMed]

44. Fiese, B.H.; Jones, B.L. Food and Family: A Socio-Ecological Perspective for Child Development. Adv. Child Dev. Behav. 2012, 42, 307-337. [PubMed]

45. Corvalán, C.; Garmendia, M.L.; Jones-Smith, J.; Lutter, C.K.; Miranda, J.J.; Pedraza, L.S.; Popkin, B.M.; Ramirez-Zea, M.; Salvo, D.; Stein, A.D. Nutrition Status of Children in Latin America: Nutrition Status of the Latin American Region. Obes. Rev. 2017, 18, 7-18. [CrossRef] [PubMed]

46. ReliefWeb. Presidente Sanchez Ceren lanza Politica Nacional de Seguridad Alimentaria y Nutricional 2018-2028-El Salvador. Available online: https:/ / reliefweb.int/report/el-salvador/presidente-s-nchez-cer-n-lanza-pol-tica-nacional-de-seguridadalimentaria-y (accessed on 12 March 2020).

47. Théodore, F.L.; Moreno-Saracho, J.E.; Bonvecchio, A.; Morales-Ruán, M.d.C.; Tolentino-Mayo, L.; López-Olmedo, N.; ShamahLevy, T.; Rivera, J.A. Lessons Learned and Insights from the Implementation of a Food and Physical Activity Policy to Prevent Obesity in Mexican Schools: An Analysis of Nationally Representative Survey Results. PLoS ONE 2018, 13, e0198585. [CrossRef] [PubMed]

48. Hilari, C.; Franco, M. What Is Needed to Improve Food Sales in Schools? Food Vendors' Opinion from El Salvador. Front. Public Health 2015, 3, 168. [CrossRef] [PubMed]

49. Amanzadeh, B.; Sokal-Gutierrez, K.; Barker, J.C. An Interpretive Study of Food, Snack and Beverage Advertisements in Rural and Urban El Salvador. BMC Public Health 2015, 15, 521. [CrossRef] 
50. Country Report: El Salvador. Available online: https:/ /www.paho.org/salud-en-las-americas-2017/?page_id=119 (accessed on 16 December 2020)

51. Wallerstein, N.; Duran, B. Community-Based Participatory Research Contributions to Intervention Research: The Intersection of Science and Practice to Improve Health Equity. Am. J. Public Health 2010, 100, S40-S46. [CrossRef]

52. Weisstaub, G.; Aguilar, A.M.; Uauy, R. Treatment and Prevention of Malnutrition in Latin America: Focus on Chile and Bolivia. Food Nutr. Bull. 2014, 35, S39-S46. [CrossRef] 